Revista da

\title{
A REFORMA DA UNIVERSIDADE
}

Eunice R. Durham 


\section{INTRODUÇĀO}

O problema que se coloca hoje para todos aqueles que defendem o ensino superior no Brasil não é, propriamente, o de definir a universidade que queremos. Em termos gerais, há uma grande concordância sobre a universidade que desejamos; é aquela capaz de oferecer um ensino diversificado, de alta qualidade, aberta a todas as classes sociais, adequado às necessidades do desenvolvimento econômicosocial do país e capaz de contribuir para a formação da pessoa e do cidadão; queremos uma instituição na qual o ensino esteja associado à pesquisa, onde a produção científica e cultural contribua para o desenvolvimento da tecnologia e para o diagnóstico dos problemas nacionais.

O problema verdadeiro está em saber por que não temos a universidade que queremos. Por diversas vezes, na nossa história, tivemos a ilusão de criar por decreto a universidade ideal, imaginando que a perfeição dos planos é, por si só, capaz de engendrar uma realidade nova. Esquecemos que a universidade, como toda instituição, é um produto histórico, no qual se solidificam interesses e práticas sociais complexos e contraditórios, que não podem ser resolvidos por decreto. Por isso mesmo, a proposta de uma nova reforma universitária deve partir da análise de como chegamos a produzir essa universidade que já temos. Devemos perguntar a que interesses ela atendeu, qual o papel do Estado na sua formação e quais os grupos e categorias sociais que a sustentaram e modificaram.

Essa análise histórica é tão mais importante porquanto a institucionalização do ensino superior no Brasil acompanhou muito de perto as grandes transformações politicas do país. Criado no início do século XIX por D. João VI, com o fim do período colonial, o ensino superior ampliou-se e se alterou substancialmente na 1a República. $O$ projeto da universidade marca o período de efervescência política e cultural da Revolução de Trinta e da instauração do Estado Novo. 0 movimento de reforma universitária é concomitante às transformações e lutas políticas da década de sessenta. E é, certamente, a crise do regime autoritário e a difícil transição do momento atual que estabelecem os parâmetros de uma nova proposta de reforma.

Isso mostra duas coisas: a estreita dependência do ensino superior brasileiro em relação ao Estado e sua sensibilidade às grandes 
transformações da sociedade. Mostra ainda, como lembra Oliveira, com muita razão, "a tendência à persistência de formas organizacionais como uma espécie de imprinting ou marca de nascença, das quais as instituições dificilmente se libertam. Em grande medida, os dilemas e conflitos enfrentados pelas instituições universitárias são tributárias de suas origens" (Oliveira, pág. 120).

\section{As marcas de origem}

Convém examinar um pouco melhor essas origens: o sistema de escolas ou faculdades autônomas, organizadas para a formação de profissionais liberais, iniciado por D. João VI. Trata-se, em primeiro lugar, de uma iniciativa do Estado para a sociedade. $O$ novo regime criado com a transferência da corte toma a iniciativa de satisfazer uma demanda difusa, antecipando-se a reivindicações articuladas de grupos sociais concretos.

O projeto é claramente elitista. Destina-se a formar e legitimar as camadas dirigentes necessárias ao novo regime. É tão elitista que a criação desse sistema público de ensino superior antecede qualquer iniciativa no sentido de proporcionar uma instrução pública elementar à população em geral. $O$ sistema é altamente centralizado e controlado pelo Estado, que determina quais as instituições a serem criadas e qual o objetivo, regulamentando minuciosamente o curriculum, os programas, a forma de escolha dos professores e diretores, assim como a remuneração(1) Trata-se enfim de um sistema voltado para o ensino, que assegura um diploma profissional, o qual dá direito a ocupar posições privilegiadas no restrito mercado de trabalho existente e assegurar prestígio social. Para isso, o sistema depende de uma ação paralela do Estado no sentido de regulamentar as profis. sões dos portadores de diploma.

Essas tendências constituem a marca de nascença do ensino bra-

(1) O controle do Estado é tão grande que, como mostra Mattos "O ensino superior foi mantido até 1878 (Reforma Leôncio de Carvalho), como exclusivamente público e privativo do Poder Central A Constituição da República descentralizou-o aos Governos Estaduais, mantida federal a legislação básica ., aliás, bastante restritiva." (Mattos, 1985, pág. 17). O artigo desse autor contém uma excelente análise da ten. dência burocrática centralizadora do nosso sistema de ensino superior. Assim, quando se defende hoje o ensino público e gratuito, é importante tomar cuidado para que isso não recrie o monopólio federal sobre a educação superior. 
sileiro: a importância fundamental do Estado, sua ação no sentido de uma estreita regulamentação burocrática e uma demanda social por ensino, que exige do sistema a garantia de prestígio social através do acesso a profissões regulamentadas e bem remuneradas.

Apesar de seu caráter antiquado (considerando-se que, em 1811, Wilhelm von Humboldt fundava a Universidade de Berlim, baseada na concepção revolucionária da associação do ensino com a pesquisa científica), a iniciativa mostrou-se muito adequada à realidade brasileira. O tripé formado pelas escolas de Direito, Medicina e Politécnica, que se constituíram na espinha dorsal do sistema, cumpriu funções sociais importantes.

As Faculdades de Direito, por bem mais de um século, formaram a elite política e a grande parte dos escalões superiores da burocracia imperial e republicana. $E$ o fizeram definindo os termos, a estrutura e o estilo do debate político e da linguagem do poder.

As Faculdades de Medicina cumpriram outro papel. Constituíram o núcleo de elaboração de uma visão laica e cientificista da sociedade brasileira que foi muito importante, especialmente no período republicano. A raça e a higiene foram os pólos que organizaram e legitimaram uma ação "saneadora" do Estado sobre a sociedade, constituindo elementos fundamentais do pensamento conservador dedicado à construção da unidade nacional. Por isso mesmo, os médicos constituem a tecnocracia da República Velha.

As Escolas Politécnicas forneceram o domínio da tecnologia necessária para prover o desenvolvimento da economia agro-exportadora, em associação como o know-how e o capital estrangeiro: a construção das estradas e a reurbanização das cidades.

Nesse sistema, o ensino das ciências, tanto quanto o cias humanidades, sempre esteve subordinado à necessidade de conceder um diploma que permitisse o exercício de uma profissão. A pesquisa que se realizava dentro desse contexto (e houve) era sempre marginal às finalidades próprias da instituição.

A pesquisa científica se abrigou em uma série de outras instituições - os museus, os observatórios, os institutos de pesquisa, todas elas extremamente frágeis, dependendo das vicissitudes do apoio do Estado. Floresceram realmente aqueles que se legitimaram em termos de uma utilidade prática imediata, como as dedicadas ao combate das 
epidemias humanas e ao desenvolvimento da produção agrícola lo Instituto de Manguinhos, o Butantã, o Instituto Agronômico de Campinas, entre outros)(2). Essa é uma outra tendência que influi posteriormente na universidade - a tendência governamental de exigir da pesquisa uma orientação prática clara.

\section{A criação das universidades}

A transformação renovadora desse velho sistema ocorre com a revolução política da década de trinta(3). O projeto de universidade que se formula e se implanta nessa época (em oposição às faculdades isoladas) está profundamente marcado pelo modelo dá universidade humboldtiana (já velho de um século) e faz parte de um grande movimento de modernização cultural, que acompanha de perto o impulso de urbanização e industrialização que põe em cheque a sociedade tradicional.

Nesse projeto, a universidade não é mais apenas um centro de formação de profissionais liberais, mas deve se constituir em um lugar de produção de conhecimento, de pesquisa ou, como se insistia na época, no "saber desinteressado", isto é, liberado de uma aplicação imediata(4).

Esse tipo de universidade não se constitui como uma iniciativa clarividente do Estado. Também não se formou a partir de uma demanda de amplos setores da sociedade, nem de reivindicações do pessoal das instituições de ensino superior existente; foi antes uma iniciativa de grupos de intelectuais - pesquisadores e educadores - que estando em geral afastados do ensino superior, constituem um movimento social. Mas os componentes desse grupo estão muito próximos do Estado e atuam junto a ele. A Universidade se implanta através de confrontos, negociações e compromissos que se dão entre intelectuais

(2) Sobre esse desenvolvimento da pesquisa, é fundamental o trabalho de Schwartzman, 1979.

(3) Essa colocação corresponde a uma versão simplificada da evolução do sistema de ensino superior, uma vez que houve transformações importantes no periodo republicano. No sistema federativo característico da Velha República há uma diferenciação progressiva, com base em experiências locais, cujos exemplos mais importantes talvez sejam os casos do Paraná e do Rio Grande do Sul.

(4) Em outro trabalho, examinei mais detalhadamente esse processo (Durham, 1986). 
e setores "esclarecidos" das classes dominantes, que possuem interlocutores ou representantes da própria burocracia estatal. Essa negociação é extremamente complexa, pois se dá num momento de transformação do regime político de tal forma que os proponentes da reforma se encontram às vezes integrados nos grupos dominantes, às vezes em oposição a ele. A atuação de figuras como Anízio Teixeira, Fernando de Azevedo, Armando Salles de Oliveira e Júlio de Mesquita demonstra a complexidade política desse processo e a importância da participação de setores da classe dirigente na implementação do projeto. A universidade acaba sendo criada através de um compromisso entre esses combatentes e os defensores do antigo sistema de ensino superior, que é realizado por imposição do poder central fortalecido nesse momento de mudança de regime(5).

O compromisso consiste num modelo institucional que preserva boa parte da autonomia das antigas escolas, mas integra-as numa unidade maior que inclui uma formação nova: a Faculdade de Filosofia, Ciências e Letras. Nesse sistema, a Universidade é uma federação de escolas, umas das quais (a FFCL) se constitui como uma mini-universidade.

Esse tipo de compromisso entre uma vanguarda intelectual e os interesses conservadores dos integrantes do sistema anterior constitui, também, um compromisso com as demandas sociais. Essas continuam a prestigiar o antigo modelo de faculdades que formam profissionais liberais. Convém lembrar que uma das grandes dificuldades iniciais da nova Faculdade de Filosofia foi exatamente a de atrair alunos que justificassem a manutenção dos cursos. Por isso mesmo, essa Faculdade, concebida inicialmente como um centro de altos estudos, acabou por incorporar uma função profissionalizante que lhe garantiu a sobrevivência: a formação de professores para o ensino médio.

Esse problema diz respeito diretamente à dificuldade de implantação da pesquisa nas universidades então criadas, apesar disso ser um dos objetivos centrais do novo sistema. $O$ desenvolvimento da pesquisa não faz parte das demandas imediatas articuladas pelos segmentos da sociedade que constituem a clientela da universidade. Por isso mesmo, a pesquisa só se institucionalizou e sobreviveu naqueles

(5) O excelente trabalho de Schwartzman, Bomeny e Costa sobre Capanema demonstra muito bem a natureza desse processo (Schwartzman e outros, 1984). 
lugares onde foi possível uma aliança entre grupos intelectuais emergentes, abertos à influência da comunidade científica internacional, e setores das classes dirigentes e do aparelho de Estado sensíveis à influência desses grupos. Isto é, a pesquisa, sendo uma necessidade difusa da sociedade, sempre dependeu fortemente de um apoio governamental, único lugar onde essa demanda poderia se cristalizar.

Por isso mesmo, o ideal de uma universidade que aliasse ensino e pesquisa só se realizou de modo muito parcial e apenas em algumas regiões do país. Ele teve razoável êxito em São Paulo, e não por acaso. Centro do processo de transformação econômica do país, São Paulo pode ser considerado, nesse momento, um dos pólos de modernização cultural que é conseqüência da urbanização e das profundas transformações da estrutura de classes. A fundação da USP encontrou sólido apoio nos setores progressistas das classes dominantes, conscientes da necessidade de formação de novas elites - os quadros para a transformação da economia e do aparelho de Estado que estavam em curso. É nesse contexto cultural que a noção de pesquisa, a investigação científica dos processo sociais, do domínio das ciências básicas encontram suporte, pois são concebidas como alicerces do desenvolvimento tẹcnológico e do planejamento social.

Ao lado do apoio de segmentos do aparelho de Estado, o desenvolvimento da pesquisa exige, contraditoriamente, uma autonomia bastante ampla que garanta sua preservação de ingerências políticas diretas e pressões imediatistas. A construção dessa autonomia se dá através do fortalecimento de valores acadêmicos fundados no reconhecimento da competência - implica o estabelecimento de um poder acadêmico que deve ser respeitado pelo Estado.

Uma das conseqüências mais interessantes e contraditórias da reforma do ensino superior da década de trinta é que, sendo concebida e implantada dentro do mais rígido padrão centralista, teve como resultado uma efetiva diversificação do sistema universitário. 0 próprio caráter ambíguo do modelo, que combinava diferentes visões de ensino superior. permitiu que ele se concretizasse de forma diversa, privilegiando um ou outro de seus componentes.

Nas regiões mais tradicionais do país, o velho sistema de ensino superior profissional era muito mais adequado aos interesses e aspirações das oligarquias locais. Mais ainda - como o ensino superior constituía uma importante fonte de recursos federais para a econo- 
mia regional, ele passou a ser também um instrumento fundamental para o exercício do clientelismo próprio desse sistema de dominação. Dessa forma, as universidades jamais conseguiram o grau de autonomia necessário para a implantação de sólidos critérios acadêmicos na organização interna do poder. As cúpulas universitárias foram monopolizadas pelos docentes mais estreitamente vinculados aos interesses políticos dominantes e raramente se mostraram sensibilizadas pela necessidade de amparar a pesquisa.

A questão da carreira se apresenta, nesse contexto, como exemplar. Foi a precoce institucionalização, na FFCL da USP, do modelo francês de doutoramento como exigência prévia para o concurso de catedrático, que garantiu a dedicação à pesquisa da geração de jovens assistentes brasileiros que veio substituir os professores contratados no exterior. Na grande maioria das universidades brasileiras, onde os cargos de titular foram precocemente preenchidos com docentes provenientes das escolas profissionais e o doutoramento não foi instituído, os mecanismos dos concursos públicos não foram suficientes para garantir a renovação intelectual e a prática sistemática da pesquisa além do mais, facilitaram a constante ingerência de critérios políticos no acesso às posições de mando e prest ígio e a hegemonia dos valores das classes dominantes tradicionais.

Mas, mesmo nas situações em que a nova universidade não conseguiu institucionalizar a pesquisa, as Faculdades de Filosofia tiveram um papel importante contribuindo para alargar o horizonte intelectual da formação universitária e ampliando o acesso ao ensino superior. Além disso, através de seu aproveitamento para a formação de professores dos ginásios e escolas normais, estabeleceu um vínculo entre os diferentes níveis do ensino público, num quadro de transformação de todo o sistema educacional. Essas novas oportunidades de acesso ao ensino superior e de carreira no magistério ajudaram a criar uma nova demanda, que foi amplamente explorada pelas novas classes médias urbanas em formação. A nova universidade representa por isso, e apesar de tudo, uma democratização (embora relativa) do ensino superior.

\section{A reforma da universidade}

O modelo híbrido de universidade, resultado de um compromis- 
so entre concepções antagônicas do ensino superior, durou uma geração.

Nos trinta anos que se seguiram à criação da universidade a sociedade mudou rapidamente e se ampliaram extraordinariamente os setores médios próprios de uma formação social, industrial e urbana. As demandas dessas camadas em ascensão foram, inicialmente, pela ampliação do ensino público de grau médio. A satisfação dessa necessidade criou uma nova clientela para o ensino superior.

Por outro lado, o desenvolvimento das burocracias estatais e das empresas capitalistas de grande porte abriu um novo mercado de trabalho ardentemente disputado pelas classes médias. $O$ diploma de ensino superior constitui uma garantia de acesso a esse mercado. $O$ veIho sistema universitário, com seus cursos fechados, currículos e programas antiquados e reduzido número de vagas mostrou-se incapaz de fazer face a essa demanda explosiva.

$\dot{E}$, portanto, mais uma vez, a demanda por ensino (e não por pesquisa) que impulsionou a reforma da universidade na década de sessenta. Nesse momento, entretanto, ao contrário do que sucedeu antes, a iniciativa parte da sociedade. Não de setores intelectuais próximos ao aparelho do Estado, mas de um movimento de estudantes que se articula, inicialmente, com a reivindicação da participação estudantil (greve do $1 / 3$ ) e exigência de reforma, e ganha novo impulso com a questão dos excedentes $(6)$

A luta pela reforma universitária na década de sessenta, se bem que expresse uma demanda social concreta das classes médias pela ampliação do acesso ao ensino superior (e assim encontrasse amplo apoio social), possui uma dinâmica específica, na medida em que se concretiza de bojo do movimento estudantil. Relaciona-se, de um lado, com um movimento de âmbito mundial que é a expressão de uma crise profunda da sociedade capitalista e corresponde à exaustão dos modelos de desenvolvimento que legitimaram as estruturas de poder construídos no pós-guerra. Tem assim o sentido de uma ampla revolução cultural e de contestação dos valores tradicionais que ordenam as práticas sociais. De outro, insere-se no processo de ruptura politi-

(6) Sobre a reforma, o trabalho anterior já citado contém uma análise mais aprofundada e uma bibliografia mais ampla (Durham, 1986). 
ca que caracteriza o Brasil nessa década e articula-se com o movimento de oposição ao regime militar.

Tanto em 60 como em 30, temos movimentos de reforma gestados em períodos de liberdade política que são implementados por regimes autoritários que se lhe seguiram. Mas, enquanto em 30 se tratava de um movimento de um grupo restrito de intelectuais que mantinham vínculos importantes com o aparelho de Estado durante todo o período de mudança do regime, em 60 temos um movimento mais amplo, organizado por segmentos não apenas distanciados do aparelho de Estado mas em aberta oposição. Paradoxalmente, entretanto, o Estado continua a ser o interlocutor, pois é dele que se exige a mudança. Assim, mais uma vez, o encaminhamento da reforma do ensino contém, subrepticiamente, um fortalecimento do poder central na medida em que a organização da universidade é tratada como questão de planejamento estatal centralizado.

Por outro lado, quando se examina a dinâmica do movimento, verifica-se claramente que o conteúdo anárquico da revolução cultural é sobrepujado por um projeto vanguardista de transformação política da sociedade. Os estudantes se julgam detentores de um conhecimento privilegiado sobre a sociedade, que lhes permite identificar-se com os "verdadeiros" interesses do povo, o qual deve ser esclarecido e liderado. Trata-se portanto, mais uma vez, da proposta de formação de novas elites para dirigir o país.

A gravidade da situação de confronto com o regime e da repressão governamental, que acabou por destroçar o movimento estudantil, não nos devem impedir de reconhecer que as demandas por reforma da universidade encontraram ressonância em setores importantes do aparelho de Estado, os quais desenvolveram paralelamente ou encamparam seletivamente muitas das propostas que partem dos estudantes e dos docentes. Assim, a reforma finalmente outorgada pelo regime contém muitos dos elementos fundamentais das reivindicações gestadas nos meios acadêmicos.

A reforma foi profunda: reafirmou a indissociabilidade entre ensino e pesquisa; aboliu a cátedra e criou os departamentos; estruturou a carreira; implantou o sistema de institutos; estabeleceu a organização do currículo em duas etapas: o básico e o profissionalizante; decretou a flexibilidade curricular com o sistema de créditos, o curso 
parcelado e o regime semestral; estabeleceu um duplo sistema de organização, com os colegiados de curso de um lado, as congregações de outro; ampliou a participação estudantil e das categorias docentes nos colegiados superiores.

Dentro desse esquema, era possível organizar uma universidade bastante próxima dos ideais da reforma. Mas, na prática, as coisas funcionaram de modo diverso. Fazendo um balanço após quase 20 anos verifica-se que não houve uma melhoria de ensino; que a flexibilidade curricular é apenas formal; que a fragmentação da universidade se agravou; que a pesquisa se manteve limitada a alguns poucos centros e, nesses, desligada do ensino. A tarefa com a qual nos defrontamos hoje é entender os descaminhos dessa reforma.

Nessa análise, três processos devem ser considerados.

0 primeiro diz respeito à deslegitimação do sistema. Como vimos, a universidade criada pela reforma incluía medidas de efetiva democratização interna e substancial aumento da participação de estudantes e docentes na gestão da instituição. Incluía ainda medidas que promoviam o fortalecimento de valores acadêmicos (a estruturação da carreira e a valorização da pesquisa). Dada, entretanto, a profunda cisão que ocorrera entre as bases desse sistema (alunos e docentes) e o regime, a nova estrutura universitária, exatamente na medida de sua vocação democrática e de fortalecimento de valores acadêmicos, dificultava o controle ideológico e político por parte do regime autoritário. Em função disso, montaram-se mecanismos paralelos, não acadêmicos, de controle político-ideológico que se constituíram como elemento corruptor e perturbador de todo o sistema. Esses sistemas compreendem, de um lado, a repressão policial direta e a triagem ideológico que age através de órgãos ilegais acoplados à estrutura de poder da universidade; de outro, o processo de centralização burocrática crescente, que garante um controle cada vez mais completo sobre o funcionamento da universidade; e, finalmente, a utilização de influências políticas no mecanismo de escolha dos dirigentes, através da manipulação do sistema de listas sêxtuplas, garantindo a permanência, na gestão da universidade, de simpatizantes do regime.

A operação desses controles abre caminho para todas as formas de ingerências ilegítimas e permite o alijamento de boa parte da liderança intelectual da universidade de qualquer participação maior no 
governo da instituição, favorecendo os docentes protegidos pelo governo central ou pelas oligarquias locais aliadas ao regime. Os valores acadêmicos da competência no ensino e capacidade de pesquisa influenciam muito pouco na escolha dos dirigentes. Enfraquecem-se os sistemas de mérito, que a estruturação da carreira deveria revigorar, destrói-se a autonomia e fortalecem-se os sistemas de cooptação e clientelismo. Nesse processo, docentes e estudantes refugiam-se numa postura de oposição intransigente e, atribuindo "à ditadura" todos os males da universidade, eximem-se de uma reflexão mais aprofundada sobre os problemas que ela enfrenta. Paralelamente, expressam simbolicamente sua resistência ao regime, defendendo um igualitarismo radical que contribui, de um outro modo, para deslegitimar os valores acadêmicos relacionados ao reconhecimento do mérito e da competência.

A preservação da qualidade do ensino e a manutenção dos grupos de pesquisa dependeram muito da capacidade das diferentes universidades de fazer frente a essa pressão. Foram fatores importantes nessa resistência a capacidade de negociar com o regime, a escolha de dirigentes mais qualificados, uma distância maior em relação aos centros de decisão (como foi o caso das universidades estaduais) e, paradoxalmente, o próprio conservadorismo da universidade, na medida em que preservou uma tradição baseada em valores acadêmicos e defendeu a autonomia da instituição. Mas, de modo geral, a pressão do regime autoritário que se exerceu através do MEC, com a colaboração dos seus prepostos colocados na direção das universidades, perpetuou e mesmo agravou a cisão entre essas cúpulas de um lado e, de outro, as lideranças intelectuais e a grande massa de estudantes e docentes que não tinham acesso aos mecanismos paralelos de poder, através dos quais as decisões realmente importantes eram tomadas.

$O$ segundo processo que precisamos analisar diz respeito ao mo do pelo qual o Governo atendeu à explosiva demanda pelo ensino superior, que havia sustentado o movimento de 68. Isso foi feito de duas maneiras: pela ampliação das vagas no ensino público e pelo estímulo à enorme expansão do setor privado.

No nível superior público, a extensão do sistema se deu através da multiplicação do mesmo elenco restrito de cursos e implicou a ampliação dos quadros docentes, sem maiores preocupações com exi- 
gências de qualificação acadêmica. Ampliaram-se assim as oportunidades de emprego no ensino superior e, concomitantemente, as possibilidades de manipulação clientelistica dessas oportunidades.

Por outro lado, como essa expansão ocorreu dentro dos rígidos sistemas de controle burocráticos que impediam a flexibilidade necessária para a reorganização do corpo docente, criaram-se sistemas paralelos de contratação, produzindo uma enorme heterogeneidade na remuneração do trabalho.

As diferentes faces desse processo contribuíram para desvalorizar ainda mais os critérios acadêmicos: pela absorção de pessoal pouco qualificado; pela manipulação de influências clientelísticas e políticas nas contratações; e pela introdução de diferenciais de remuneração e de condições de trabalho que nada tinham a ver com exigências de competência e desempenho. As bases acadêmicas da carreira universitária, que haviam sido instituidas com a reforma, foram solapadas. A regularização dessa situação em 1980, feita em termos de atender os reclamos mais corporativos do corpo docente, acabou por destruir, na prática, todo o sistema de mérito fundado na titulação.

A expansão do ensino público atendeu apenas uma parte da demanda crescente. A outra foi absorvida pelo setor privado, que recebeu fortes estímulos e incentivos nesse periodo. Toda a década de 70 é marcada por um enorme crescimento desse setor(7)

A expansão do ensino privado é governada pelas leis do mercado e está portanto condicionada aos elementos mais imediatos da demanda social, que se orienta no sentido da obtenção do diploma. Cria-se assim um sistema empresarial de ensino no qual a qualidade da formação oferecida é secundária e a pesquisa totalmente irrelevante.

Essa forma de atendimento da demanda, que afeta tanto o sistema público como o privado, reforça componentes extremamente conservadores da nossa concepção de ensino superior, que associa a formação universitária ao acesso a profissões regulamentadas e se apóia na tentativa de preservar ou conseguir posições de privilégio. Reforça também as pressões no sentido da regulamentação das profissões, fortalecendo as tendências cartoriais do aparelho de Estado e os

(7) Sobre o desenvolvimento do ensino privado, de duas perspectivas opostas, consulte-se Tramontin e Braga (1985) e Cunha (1985). 
componentes hierárquicos da vida social. Como o mercado de trabaIho não pode se estruturar dessa forma, esse tipo de atendimento alimenta uma ilusão e deforma o sistema de formação em nivel superior.

Uma universidade aberta a amplas camadas da população não pode ser construída simplesmente multiplicando a matrícula nos mesmos cursos tradicionais, preservando a velha concepção de diploma profissional e conservando o mesmo tipo de ensino. Não se pode abrir as portas da universidade para transformar todos em advogados, médicos e engenheiros. Também não faz sentido multiplicar o número de sociólogos, filósofos, jornalistas, fono-audiólogos e psicólogos que engrossarão as filas de desempregados num mercado de trabalho já saturado desses profissionais. $O$ diploma de ensino superior continuou a ser uma vantagem diferencial no mercado de trabalho, mas apenas en termos de seu valor genérico, como atestado de formação em nível universitário, não como um certificado de qualificação profissional específica.

Ocorre assim um distanciamento crescente entre a pseudo-formação profissional que o estudante recebe na universidade e as funções que desempenhará na sua vida profissional real.

A ampliação do acesso ao ensino superior exigia uma ampla reforma curricular, que não ocorreu. Nem a universidade, nem o Ministério foram capazes de promover uma efetiva reforma do ensino que deveria ter acompanhado a reforma da universidade.

A ampliação do sistema de ensino superior deveria ter sido feita através de uma profunda alteração da estrutura da oferta, diversificando os cursos de forma a atender uma clientela cada vez mais heterogênea. Em lugar de diversificar o tipo de curso, o que se fez foi diversificar a qualidade de cursos formalmente iguais.

Como todo o processo foi acompanhado de uma ampliação e deterioração paralelas ao ensino público de 10 e 20 graus, estabeleceu-se o sistema perverso, tantas vezes denunciado, no qual o acesso às instituições de melhor nível, em geral públicas e gratuitas, passa a ser monopolizado pelos segmentos sociais capazes de financiar uma escolarização melhor para os filhos nos 10 e 2.9 graus. Os estudantes mais pobres, egressos da escola pública, só conseguem vagas nos estabelecimentos de pior qualidade, em geral particulares e pagos. Reforça-se desse modo o elitismo do sistema, reproduzindo a situação cria- 
da por D. João VI, de um sistema de ensino superior público e gratuito destinado às camadas privilegiadas da população.

Esse desenvolvimento teve efeitos políticos claros. Desmobilizou as bases sociais que haviam alimentado a reivindicação de democratização do acesso ao ensino superior.

$\mathrm{O}$ terceiro processo diz respeito à pesquisa.

Já afirmamos anteriormente que o desenvolvimento da pesquisa não faz parte das demandas imediatas de nenhum setor mais amplo da sociedade civil (nem do aparelho de Estado em seu conjunto), a não ser sob a forma limitada de tecnologia ou de levantamentos sociais de aplicação imediata.

A pesquisa, especialmente a pesquisa básica, atende a necessidades gerais da sociedade moderna, promovendo o domínio, pelo conhecimento, dos processos naturais e sociais. Nesse sentido não fornece vantagens sociais ou econômicas imediatas para grupos sociais concretos (a não ser os próprios pesquisadores), mas se constitui como pré-condição genérica do desenvolvimento que só pode ser ativada pela mediação da tecnologia e da política. A percepção de sua importância só pode se cristalizar como demanda por grupos que ocupam posições nas quais são forçados a refletir sobre as necessidades da sociedade em seu conjunto e não sobre os interesses imediatos de segmentos sociais concretos. A preocupação com a pesquisa tende portanto a ser característica de grupos intelectuais restritos e de certos segmentos mais intelectualizados das classes dirigentes, que encontram expressão em setores específicos do aparelho de Estado. $O$ desenvolvimento da pesquisa sempre dependeu da aliança entre esses segmentos. Embora eles freqüentemente estivessem, pelo menos no Brasil, em campos políticos opostos, essa aliança tem sido mantida de alguma forma.

A política geral do ensino superior desenvolvida pelo MEC esteve voltada, no período que estamos analisando, para o atendimento das demandas sociais imediatistas por ensino e para o controle de rendimento político desse atendimento. A preocupação com o desenvolvimento da pesquisa em sua relação com o ensino não fez parte dessa política geral, mas se canalizou para um segmento específico do ministério, a CAPES, e para outros organismos que se expandiram e 
solidificaram nesse período: as agências financiadoras como o CNPq, o Programa FUMTEC do BNDE e, mais tarde, a FINEP(8)

Nesses organismos, a pressão ideológica e clientelística que afetou tão profundamente o sistema de ensino não pode se exercer de modo a invalidar ou destruir os critérios de qualidade. Esses órgãos também não puderam prescindir da participação da comunidade científica. Manteve-se, nesse campo, um sistema de pressões e negociações cujo instrumento fundamental foi a consolidação de um sistema de avaliação. Não que o sistema tenha ficado imune à manipulação clientel ística, à discriminação ideológica ou não tenha operado freqüentemente como uma forma de mecenato. Mas o sistema de avaliação, baseado em critérios de qualidade e exercido num sistema de julgamento por pares, estavelceed uri: hizar reciprocamente reconhecido como legítimo de comunicação entre o aparelho de Estado e a comunidade científica.

$\mathrm{Na}$ deterioração generalizada do sistema de ensino superior, o desenvolvimento da pesquisa se deu através do apoio desses organismos, que estabeleceram um sistema paralelo à estrutura universitária, entrando diretamente em contacto com os pesquisadores (organizados na pós-graduação ou nos grupos de pesquisa). Esse sistema age por cima e por fora da estrutura de poder da universidade. Na medida em que ele se legitima em função da qualidade da produção científica e da competência dos pesquisadores, fortalece os valores acadêmicos; mas o faz dissociando o lugar do reconhecimento desses valores da gestão da universidade em seu conjunto. O funcionamento desse sistema se dá no sentido de criar e manter "ilhas de competência", que aparecem como quistos no tecido da mediocridade generalizada das instituições universitárias(9).

Os grupos de pesquisa se desenvolverám, portanto, mantendo canais de comunicação com o Estado, ao contrário do que ocorreu na universidade enquanto instituição, dominada pelas tarefas do ensino, onde as cúpulas universitárias e o ministério se divorciaram đa ba-

(8) É importante lembrar que, durante quase toda a década de setenta, a pesquisa nas ciências humanas esteve, antes da dependência de instituições estrangeiras como a Fundação Ford, do que as agências financiadoras do Estado, o que é claramente conseqüência do clima politico da época.

(9) A expressão "ilhas de competéncia" é tomada do livro de João Batista Araújo e Oliveira, que contém uma abordagem muito inovadora sobre as instituições de ensino superior (Oliveira, 1985). 
se formada pelos docentes e estudantes, os quais se viram marginalizados dos órgãos de decisão e sem canais legítimos de negociação.

Mas não é só isso. Quando se examina o panorama geral do desenvolvimento da pesquisa, especialmente nas regiões mais desenvolvidas, o que se nota é a multiplicação de mecanismos paralelos às organizações universitárias públicas, sob a forma de fundações, centros e instituições privadas ou semi-privadas, que competem vigorosamente pela apropriação de parcelas importantes do fundo público destinado à pesquisa. Ao mesmo tempo, os organismos federais parecem incentivar a criação de novas instituições públicas, independentes do sistema de ensino.

Observa-se, portanto, uma tendência preocupante de desligamento progressivo da pesquisa em relação ao ensino, que manifesta sua dificuldade em sobreviver dentro da estrutura universitária.

O resultado da operação desses três processos foi uma profunda diversificação de todo o sistema de ensino superior que esconde, sob a roupagem burocrática-formal do modelo único de universidade, uma enorme diferença de qualidade (10).

Temos, em um extremo, os estabelecimentos que atendem da forma mais imediatista a demanda por diploma, voltados para um ensino de massa, ignorando a pesquisa - nesse extremo, se encontram muitas das empresas de ensino e um setor do sistema público, no qual se incluem algumas instituições municipais. No polo oposto, estão as universidades ou estabelecimentos isolados que, logrando preservar, pelo menos setorialmente, a indissociabilidade entre ensino e pesquisa, mantendo critérios relativamente severos de qualificação acadêmica, oferecem as melhores oportunidades de formação - entre esses encontramos algumas instituições públicas e uma pequena minoria de estabelecimentos particulares. 0 restante do sistema, que abarca a grande maioria das universidades federais, se debate entre esses dois modelos extremos, incapazes de realizar o segundo e recusando-se a decair ao nivel dos primeiros.

(10) Uma das questões fundamentais dessa diversificação, que não pode ser tratada detaIhadamente no àmbito deste trabalho, diz respeito à formação dos professores de 10 e 2 ? graus. É importante que se faça uma análise da crescente apropriação dessa tarefa pelo ensino privado (ver Tramontin e Braga, 1985) e da visivel falência do sistema de licenciatura para suprir às necessidades de formação de pessoal para um ensino básico de boa qualidade. 
A distribuição dessas diferenças segue padrões regionais. Nas regiões mais desenvolvidas do país, encontramos a maior concentração dos dois extremos do sistema: o pior e o melhor. É efetivamente nessas regiões onde coexistem, de um lado, os maiores recursos humanos, financeiros e institucionais para o ensino de melhor qualidade e para a pesquisa. $\dot{E}$ aí, também, onde se concentram as expectativas de ascenção social e a grande demanda de origem mais popular por ensino superior - essa é atendida pelas empresas que oferecem um arremedo de ensino superior. Parece portanto que o desenvolvimento desse sistema de ensino manifesta nessas regiões, de forma mais clara, os impasses de uma situação contraditória, pois, quanto mais se consegue defender a qualidade de ensino nas universidades públicas, tanto mais se afastam dela os setores populares que não tiveram acesso às escolas particulares de 10 e $2 \%$ graus - e tanto pior a qualidade do ensino que thes é oferecido nas escolas superiores particulares as quais tem acesso.

Nas regiões menos desenvolvidas concentram-se os estabelecimentos que se colocam entre os dois extremos. Em primeiro lugar, porque a escassez de capitais privados e a precariedade dos rendimentos da maioria da população impediu o florescimento das empresas de ensino. Ao mesmo tempo, o déficit crônico dos orçamentos estaduais inviabilizou a criação de um outro sistema público de educação superior, estadual ou municipal. Isso torna essas regiões fortemente dependentes do sistema federal. Por outro lado, dado o vulto desses recursos destinados à manutenção do ensino face à pobreza local, as universidades se constituem como um instrumento importantíssimo para a política clientelista que mantém no poder as oligarquias regionais, exacerbando a luta política pelo controle dessas instituições e agravando a cisão entre as bases e as cúpulas universitárias, à qual já nos referimos.

O sistema, apesar de suas contradições imensas, funcionou enquanto o crescimento econômico garantiu o retorno do capital privado investido e a ampliação dos recursos públicos para o sistema estatal, ao mesmo tempo em que a repressão política dificultava movimentos de oposição à política governamental. Mas a combinação de crise econômica com abertura propiciou a organização e expansão do movimento de contestação que vem se fortalecendo nos últimos anos. 
E dentro dessa heterogeneidade e nesse contexto político que devemos entender as reivindicações e as lutas que se travam hoje, em torno de proposta de reforma universitária.

\section{O novo movimento de reforma}

As novas propostas de mudança da universidade têm sua origem e muito de sua sustentação num novo ator político - as Associações de Docentes. Não se trata mais de grupos intelectuais "externos" ao sistema de ensino superior e próximos do Estado (como em 30), nem de um amplo movimento estudantil, com amplas ramificações políticas e raízes em setores de classe média que clamam por acesso à universidade. Temos agora, e pela primeira vez, um movimento interno e fechado dentro das instituições de ensino superior. Por isso mesmo, talvez, a maior parte das propostas até agora apresentadas visa mais a atender a interesses dos docentes do que a captar $\mathrm{e}$ atender demandas da sociedade (11).

As associações de docentes se organizaram a partir das lideranças intelectuais que haviam sido marginalizadas nas universidades públicas, em virtude de sua postura de oposição ao regime. 0 movimento se organiza como uma crítica à deterioração do ensino e da pesquisa: culpa os órgãos centrais da universidade pela situação existente, denuncia como ilegítimos os instrumentos políticos que garantem a perpetuação na cúpula universitária de uma minoria incompetente aliada ao regime. A bandeira do movimento é a democratização, concebida como ampliação da participação docente, através de mecanis, mos de representação. 0 movimento se legitima em função da defesa de valores acadêmicos e se respalda na competência científica de sua liderança. Trata-se, em suma, de um movimento através do qual grupos que gozam de prestígio intelectual na universidade, mas que foram excluídos politicamente, procuram assumir a gestão da instituição. Esse início se caracteriza pela predominância de uma orientação que podemos chamar de acadêmica.

Dada a cisão que apontamos anteriormentè entre as cúpulas

(11) Sobre o movimento docente, as fontes mais importantes são as publicações, pronunciamentos, estudos e manifestos produzidos pela ANDES e pelas associações de docentes. Para uma crítica contundente dos aspectos mais corporativos do movimento, veja-se Giannotti, 1986. 
universitárias e o conjunto de estudantes e docentes e a inexistência de instâncias de mediação, o movimento se organiza necessariamente em termos de um confronto. E como a situação existente, contra a qual se insurgem esses docentes, está amparada pelo regime autoritário, o movimento adquire, desde o início, uma conotação política mais ampla de contestação ao regime.

$\mathrm{Na}$ medida em que assume esse caráter de contestação, o movimento atrai para sua bandeira todos os setores de esquerda da universidade e seu caráter político se acentua, em consonância com a mobilização da sociedade civil que caracteriza o final da década de 70. Nesse processo, e, em virtude da presença dos setores da esquerda mais radical, o tema de democratização também se radicaliza e passa a ter uma importância quase exclusiva, constituindo o elo de ligação com os demais movimentos da sociedade civil; o vigoroso ataque às estruturas autoritárias dentro e fora da universidade deixa em segundo plano a reflexão sobre os problemas mais específicos do sistema universitário e os temas propriamente acadêmicos.

Assumindo uma postura de confronto e sendo um movimento interno à universidade, sem bases sociais mais amplas, o movimento procurou aumentar sua força na luta contra a estrutura autoritária, buscando aliados na própria instituição e estabelecendo uma aliança com estudantes e funcionários. A reinterpretação da idéia de democratização no sentido de uma participação igualitária de toda a "comunidade universitária" foi o instrumento dessa a aliança. Convém notar que essa concepção de um "igualitarismo comunitário" é muito característico dos grupos da esquerda mais radical desse periodo e permeia o conjunto dos inúmeros movimentos sociais que proliferam nessa épocal 12$)$.

Como a constituição desse movimento de associações de docentes é concomitante à progressiva redução dos fundos públicos destinados ao ensino superior, com conseqüente achatamento salarial, ele precocemente incorpora uma outra vertente - a sindicalista. Ao assumir esse caráter para-sindical de reivindicação salarial e melhoria das

(12) É importante ressaltar as afinidades do movimento docente com outros movimentos sociais desta época, com o qual compartilha o "igualitarismo comunitário" Para uma análise desses movimentos sociais e a peculiar postura face ao estado que assumem, consulte-se Cardoso 1983 e Durham 1984. 
condições de trabalho, o movimento se fortalece, altera sua composição e reforça sua aliança com funcionários, estimulando-os a constituir uma organização paralela.

Enquanto predominaram as vertentes acadêmica e estatária, o movimento congregou principalmente o setor docente mais qualificado e progressista da universidade, a quem esses temas interessavam. Com a nova orientação para-sindical as associações passam a atrair a grande massa dos docentes, independentemente de sua qualificação, de seu prévio engajamento político e de seu real interesse pelos destinos da universidade. Se, do ponto de vista dos docentes mais politizados, o engajamento na questão salarial é uma arma para a mobilização da universidade, para uma grande parte do corpo docente a contestação à estrutura autoritária e a bandeira da qualidade do ensino passam a ser utilizadas como instrumentos para legitimar a luta por benefícios econômicos. 0 movimento passa a abrigar, sob a aparência de uma união monolítica, uma grande ambigüidade interna.

O fortalecimento da vertente sindical fortalece, concomitantemente, a aliança com os funcionários, desinteressados das questões acadêmicas, mas profundamente empenhados na questão salarial. A questão da gestão da universidade passa a ser vista sob a ótica do acesso aos fundos públicos e da distribuição interna desses recursos.

Nesse desenvolvimento, a vertente propriamente acadêmica acabou ficando marginalizada. Embora as preocupações com a competência docente, a qualidade do ensino e o desenvolvimento da pesquisa sejam freqüentemente incorporados no discurso do movimento, seu papel é antes o de legitimar as reivindicações salariais, raramente dando origem a uma mobilização efetiva em torno da defesa de valores acadêmicos. Aliás, é fácil compreender que, quanto mais sindicalista o movimento, maior a incorporação dos docentes menos qualificados e dos mais desinteressados das questões acadêmicas, maior a ênfase do igualitarismo e menor a aceitação de critérios de qualificação profissional na escolha dos dirigentes universitários. Assim, as lideranças intelectuais empenhadas na defesa da competência profissional, contando com um espaço cada vez menor no movimento docente, começam a articular uma nova forma de atuação que encontrou ressonância nas sociedades científicas empenhadas na defesa da pesquisa, introduzindo um novo ator no debate sobre a reforma universitária. É importante notar que esse grupo compreende boa parte 
dos docentes engajados na pesquisa, que mantiveram tradicionalmente relações de negociação com setores do aparelho de Estado, através dos mecanismos da avaliação.

A força da vertente sindicalista ou corporativa no movimento das associações de docentes se deve, em grande parte, à posição hegemônica que nele ocupa o conjunto formado pelas universidades federais.

Dada a enorme heterogeneidade das instituições de ensino superior e, portanto, a diversidade das relações de trabalho existentes nas inúmeras instituições públicas e privadas, as reivindicações são muito diferentes e se destinam a interlocutores diversos, pulverizando-se. Nessa heterogeneidade, as universidades federais constituem um bloco numeroso e poderoso, unificados pelos interesses comuns e pelo fato de se dirigirem ao mesmo interlocutor, o MEC. Daí sua posição central no movimento. Em virtude disso, é impossível entender a natureza das reivindicações e dos impasses, se não se reconhecer que eles derivam de problemas e necessidades específicos dos estabelecimentos da rede federal.

Pelo próprio fato de estarem sob o controle direto do ministério, os estabelecimentos federais formam, de todas as instituições de ensino superior, os que gozaram de menor grau de autonomia, as mais afetadas pelo sufocante sistema de controles burocráticos e as mais diretamente sujeitas a pressões políticas e clientelisticas e, onde a cisão entre as cúpulas e as bases foi mais completa.

Em virtude dessas características estruturais, o enfrentamento, quando ocorre, se dá diretamente contra o ministério e as forças políticas que o controlam. Nessas condições, a unidade do movimento e a aliança com todos os setores da comunidade universitária se torna crucial. Apenas os interesses corporativos são capazes de promover essa unificação.

Nas universidades federais, a escolha dos dirigentes sempre esteve diretamente subordinada ao MEC e portanto muito mais sujeita às ingerências políticas e aos interesses das oligarquias locais. Nesse contexto, a luta pela eleição direta dos dirigentes assumiu uma importância fundamental, pois era a única maneira de romper os mecanismos tradicionais de dominação e estabelecer um mínimo de autonomia para a universidade. Como o ministério constituía um oponente mui- 
to forte, a aliança com funcionários e alunos tornou-se crucial. Por isso, a fórmula de eleição direta tripartida se erige como princípio indiscutível - essa fórmula é o preço e o penhor da aliança. É fácil verificar que quanto mais autoritária tenha sido anteriormente a atuação dos reitores e mais forte o apoio que receberam das forças políticas do governo, mais exarcebada e mais autêntica foi a luta pelas eleições diretas. Como, por outro lado, os mecanismos anteriores de escolha jamais privilegiaram critérios acadêmicos de competência e qualificação, tão mais facilmente puderam esses valores ser abandonados pelo movimento docente em favor das posturas do igualitarismo radical que encontrava amplo respaldo entre alunos e funcionários (para os quais, obviamente, as questões de nivel de carreira e titulação acadêmica aparecem como sutilezas de importância secundária).

Foi em termos da formação desse bloco monolítico e desse enfrentamento direto com o MEC que o movimento docente conquistou vitórias expressivas e passou a dominar o debate sobre a reforma universitárỉa. O que ficou menos visível, nesse processo, é que essas vitórias beneficiaram, quase que exclusivamente, as universidades federais. Nos outros segmentos do sistema de ensino superior, os ganhos foram muito menores. Apenas nas universidades católicas o mesmo modelo de ação produziu resultados significativos, talvez em virtude de sua legitimação pela Teologia da Libertação. A Teologia da Libertação, por assim dizer, neutralizou a capacidade de resistência das cúpulas confessionais.

Esse processo tem conseqüências políticas importantes para o encaminhamento da questão da reforma universitária. Dado o fato que as grandes vitórias se deram no enfrentamento das universidades federais com o Ministério da Educação, o movimento docente, por assim dizer, "federalizou" excessivamente a questão da universidade.

De um lado, os problemas das universidades federais são vistos como sendo os problemas do ensino superior em geral. Isso reforça, subrepticiamente, toda a tendência tradicional da política universitária brasileira de organizar o sistema de ensino em função de um modelo único, embora todas as reivindicações sejam no sentido da diversificação do sistema: as reivindicações vão num sentido, mas na prática política encaminha a solução em outro. 
Por outro lado, estabelecida uma dinâmica de enfrentamento direto com o MEC, ele se torna o interlocutor privilegiado e é dele que passam a depender todas as soluções. Fortalece-se, assim, indiretamente, o centralismo que sempre caracterizou o ensino superior brasileiro, fazendo depender do executivo federal toda a organização do sistema.

Finalmente, nesse processo, solidifica-se a tática do enfrentamento e dificulta-se a criação de mecanismos e instrumentos de negociação.

Se essas táticas e esses enfrentamentos eram necessários e inevitáveis durante o período autoritário, a abertura do regime e o estabelecimento de um processo de transição exigem novas formas de luta. O próprio da transição é que se estabeleçam canais de negociação que permitam a consolidação das práticas democráticas. E se o enfrentamento foi criado inicialmente pela recusa do regime em estabelecer instâncias de representação e negociação, a manutenção da mesma postura nessa nova situação política corresponde ao inverso: a recusa do movimento em aceitar instâncias de negociação e, pơrtanto, o enfraquecimento da possibilidade de encaminhamento democrático da questão da reforma da universidade.

Finalmente, há a considerar ainda uma questão: o enfrentamento direto docente-MEC tinha obviamente um sentido de caracterizar a ilegitimidade dos reitores nomeados, ignorando sua posição de representantes da universidade ante as instâncias externas. Com a própria vitória do movimento e a presença de reitores eleitos em muitas universidades, legitimou-se sua função de representação, que eles só podem exercer estabelecendo o diálogo e a negociação com o ministério. O movimento dos docentes, falando em nome do conjunto dos professores (e não de cada universidade) e mantendo a postura de enfrentamento, atropela a atuação dos reitores, restringindo e freqüentemente destruindo sua capacidade de ação ao impedi-los de exercer seu papel institucional de estabelecer a mediação entre o corpo docente e o aparelho do Estado. Nessas condições, apenas o Conselho dos Reitores poderia se constituir como um órgão capaz de estabelecer a mediação institucional entre as univeisidades e o MEC, organizando as instâncias de negociação que se fazem necessárias, isto é, ocupando o espaço institucional que lhe cabe, sem destruir a função de lobby que o movimento docente deve continuar a exercer. 


\section{Observações finais}

O vigor do movimento docente e a força de sua vertente parasindical contribuem para encaminhar a discussão sobre a reforma universitária em uma direção freqüentemente oculta, ou pelo menos que deixa em segundo plano alguns dos problemas mais gerais do ensino superior. Isso ocorre porque a reflexão se orienta para problemas internos à instituição e se concentra excessivamente nas questões referentes ao acesso aos recursos públicos e à forma de gestão mais adequada aos interesses da comunidade universitária. Os problemas mais gerais aos quais nos referimos exigem uma perspectiva diferente, pois decorrem das demandas da sociedade e do papel do Estado na implantação e no controle do ensino superior. Vista a questão desse ângulo, a definição da universidade que queremos deve estar subordinada às demandas que ela deve atender e ao grau de autonomia que pode conquistar.

O primeiro problema que devemos enfrentar diz respeito à dimensão quantitativa da demanda por ensino superior. $O$ crescimento da população, a urbanização, o desenvolvimento econômico e a transformação da estrutura de classes têm provocado um aumento continuado ao número de jovens que procura a universidade. É verdade que essa procura foi contida, até agora, pela inadequação e precariedade do ensino básico, que provocam altíssimas taxas de reprovação e evasão escolar muito antes dos alunos poderem chegar às portas da universidade. A melhoria do ensino de primeiro e segundo graus e a diminuição das desigualdades sociais que esperamos do regime democrático, se vierem a ocorrer, intensificarão enormemente a demanda.

Como vimos, até agora, a pressão da classe média por ensino superior vem sendo atendida através da ampliação do setor público e de uma expansão muito grande do setor privado. Desde o final da década de 70, entretanto, dadas as dificuldades econômicas do país, vem ocorrendo uma diminuição da parcela do fundo público destinado ao ensino superior, ao mesmo tempo em que o setor privado encontra dificuldade crescente em se manter dentro dos inecanismos de mercado. Nessa situação, o sistema deixou de crescer e vem sofrendo um grave descapitalização. Como resultado dessa situação, vem se constituindo uma pressão crescente, tanto do setor público 
como do privado, para a apropriação de uma parcela maior dos fundos públicos.

O ensino superior vive portanto uma situação de crise que aguça as demandas corporativas e dificulta um diagnóstico mais claro da complexidade dos problemas envolvidos. Nesse particular, o ensino superior reflete muito de perto as características desse momento de transição política, no qual as demandas setoriais se fazem sentir através de movimentos organizados, que atuam como se os fundos públicos fossem inexauriveis e suas demandas não tivessem que ser negociadas em função das reivindicações de outros setores. Não há canais de negociação que permitam uma distribuição eqüitativa de benefícios e sacrifícios. Não há, nem na sociedade nem na universidade, um pacto social que permita um encaminhamento, a mais longo prazo, da solução dos problemas atuais.

O primeiro passo nessa direção consiste em perguntar se um aumento de recursos para o sistema de educação superior, tal como existe, permitirá, por si só, um atendimento das demandas sociais concretas atuais e das necessidades de formação em nivel superior para a população brasileira no futuro (13).

O problema não é novo e já estava claramente colocado nas discussões sobre a reforma universitária que atravessaram toda a década de sessenta. E isso não só no Brasil. Também na Europa e nos Estados Unid'os, o grande movimento estudantil de 68 foi acompanhado por um processo de rápida expansão do ensino superior e provocou um amplo debate sobre o "ensino de massa" O que estava em discussão eram as formas mais adequadas para incorporar um número crescente de alunos e para eliminar os privilégios de classe no acesso à universidade.

A fórmula mais simplista que encontrou ampla aceitação nos setores de esquerda, por ser aparentemente mais democrática, foi aceita e implantada em muitos países. Consistia em multiplicar o número das universidades existentes e o número de vagas em cada uma delas, oferecendo a todos que o desejassem, aquele mesmo tipo de educação superior que, anteriormente, era privilégio de uns poucos. 0 re-

(13) Sobre a experiência de outros países com os dilemas do ensino superior de massa e a preservação de centros de excelència, veja Blume, s.d.; Schwartz, 1984; Touraine. Fischer-Appelt, 1980; Ben-David, 1977. 
sultado dessa experiência foi muito pouco satisfatório. Mesmo na França, onde o sistema de ensino de primeiro e segundo graus oferecia uma escolarização básica de excelente nível, a abertura indiscriminada das universidades provocou uma acentuada queda na qualidade do ensino superior e agravou o divórcio entre o ensino e a pesquisa, criando uma defasagem crescente entre as expectativas dos estudantes e os benefícios reais oferecidos pela formação universitária. Por outro lado, o controle crescente da universidade pelas organizações sindicais dos professores, caracterizadas por um igualitarismo militante, parece ter contribuído para agravar a crise. Preservaram-se apenas as tradicionais Grandes Écoles e reproduziu-se, desse modo, o elitismo anterior. Na Argentina, por outro lado, onde o mesmo sistema foi tentado, o resultado foi muito mais catastrófico, pois praticamente destruiu o ensino universitário.

Na Alemanha, o caminho foi diferente. Além da ampliação da rede das universidades, que preserva muito do ideal humboldtiano, criaram-se novas instituições de ensino de conteúdo mais nitidamente técnico-profissional, onde a pesquisa era antes uma prática pedagógica - essas instituições tiveram um grande sucesso e muitas delas são hoje preferidas às universidades tradicionais. A Inglaterra seguiu um caminho semelhante.

Nos Estados Unidos, onde a diversidade sempre foi muito grande e onde as universidades mais tradicionais revelaram grande flexibilidade e capacidade de adaptação, o aumento da demanda parece ter sido absorvido sem a necessidade de um completo realinhamento do sistema.

No Brasil, o golpe de 68 interrompeu o debate que estava em curso e não houve a preocupação com a diversificação. Aliás, nesse ponto, tanto o radicalismo da esquerda como o populismo de direita convergiam na defesa do modelo único para o ensino superior, que possui fundas raízes na nossa tradição histórica. Na implantação desse modelo, promoveu-se a modernização da organização interna da universidade e decretou-se a indissociabilidade entre ensino e pesquisa; preservou-se muito da tradição mais antiga da estreitá relação entre ensino universitário e profissões regulamentadas; e reconstruiramse os rígidos mecanismos de controle burocrático centralizado, que sempre caracterizaram o autoritarismo luso-brasileiro. 
Esses controles não impediram uma crescente heterogeneidade do sistema, a qual entretanto ocorreu de uma forma duplamente perversa. Em primeiro lugar, porque produziu, ao lado da universidade que se aproxima do molde ideal previamente instituído, sua contrafação: a universidade onde a pesquisa é uma ficção; onde o diploma profissional não oferece a seu portador condições de exercer a profis: são; onde a autonomia foi substituída pelas formas de domínio, próprias das oligarquias tradicionais; e, no ensino privado, instituições nas quais as mantenedoras são mantidas lucrativamente pela mensalidade dos alunos. $E$, depois porque, preservando para as camadas mais favorecidas da população as instituições mais próximas do modelo original e garantido, para elas, o ensino gratuito, relegou-se a população mais pobrè às imitaçōes pagas.

O segundo problema que se coloca, portanto, quando se fala em ensino superior é como tratar o problema dessa diversidade. A questão é importante porque a diversificação é inevitável - ela decorre de pressões sociais que são legítimas e muito fortes.

Se a diversificação do sistema de ensino, aprisionado no modelo único, resultou em tornar qualitativamente diferente o que era definido formalmente como igual, reconhecer a diversidade significa estabelecer uma política que inverta esse processo: que promova uma equivalência qualitativa (promovendo a melhoria de qualidade de todo o sistema do que deve ser formalmente e efetivamente diverso - diferentes tipos de ensino e de estabelecimentos, atendendo diferentes demandas e promovendo uma formação diversificada). É importante também que essa diversificação se dê tanto no ensino público como no privado, de forma a evitar privilégios de classe no acesso a um ou outro, criando uma espécie de reserva de mercado para o ensino pago.

Colocada a questão dessa forma, a universidade que queremos depende muito do papel que ela deve desempenhar num sistema de ensino superior amplo e diversificado.

Não seria nem necessário nem possível multiplicar universidades pelo Brasil afora, isto é, grandes instituições de ensino onde a universalidade dos campos de conhecimento esteja intimamente associada à integração entre ensino e pesquisa. Isso significaria multiplicar, por todo o país, grandes laboratórios de física, complexas instalações hospitalares, sofisticados equipamentos para a pesquisa genética ou 
micro-biológica que são próprios das grandes universidades, com o único intuito de garantir à população o acesso ao ensino superior.

O governo deve certamente continuar a manter uma rede de universidades públicas. Mas se deveria estimular também a criação de outros tipos de estabelecimentos públicos de ensino, menos complexos, mais flexíveis, capazes de cumprir de forma diversa as funções de preparação profissional e de formação educacional. A diversidade dos estabelecimentos e dos cursos significa, simultaneamente, a diversificação dos critérios de ingresso e, portanto, a possibilidade de absorção no ensino superior público de uma população mais ampla e mais heterogênea da que hoje freqüenta as universidades.

Escolas que oferecem uma formação mais nitidamente técnicoprofissional, como existem na Alemanha, não precisam oferecer um ensino inferior. Há excelentes escolas desse tipo, que possuem, inclusive, maior flexibilidade de adaptação a necessidades locais e regionais do mercado de trabalho. De outro lado, há que se pensar em instituições do tipo dos liberal-arts colleges americano, que oferecem uma formação mais humanista, mais voltada para as ciências sociais, os quais podem satisfazer muitas das necessidades das grandes burocracias estatais e privadas que hoje constituem boa parte do mercado de trabalho. Em nenhuma dessas instituições a pesquisa está excluída - particularmente necessária é a pesquisa que possui claras finalidades tecno-pedagógicas. Mas escolas desse tipo não precisam ser centros de pesquisa, no sentido estrito do termo.

Numa sociedade em rápida transformação, a outra face da diversidade é a flexibilidade. As próprias universidades estão excessivamente presas a organizações curriculares rígidas e freqüentemente antiquadas e respondem de modo muito lento às alterações da estrutura da demanda. Uma sensivel ampliação dos tipos de formação atualmente oferecidos pelas universidades seria igualmente necessária e deve ser iniciada. Essa, aliás, era uma intenção explícita da reforma de 68, que, entretanto, não chegou a se concretizar. Um instrumento importante da flexibilidade são as atividades de extensão. Não há porque restringir as atividades educativas e culturais da universidade a cursos regulamentados de longa duração. Cursos livres, de extensão, de atualização, de treinamento em técnicas especializadas, eventos culturais, são todos formas de ampliar o acesso ao ensino superior. Do mesmo modo, a própria pesquisa pode ser considerada uma forma 
de extensão porque pode responder a demandas de grupos sociais, órgãos governamentais e mesmo das empresas privadas.

Diversificar o sistema de ensino não pode ser feito dentro do rígido sistema de controles burocráticos formais que hoje caracterizam - Ministério da Educação. É particularmente incompatível com o sistema do currículo mínimo que hoje regula todo o ensino superior. A idéia de oferecer, em todo o país, os mesmos tipos de curso, é contraditória em termos de um sistema diversificado e heterogêneo, sensível às particularidades locais e regionais. Também é incompatível com a tendência à manutenção e ampliação do sistema de profissões regulamentadas, que fazem parte de nossa tradição cartorial. A alteração de todo esse sistema, que obviamente não pode ser feita da noite para o dia, implica uma transformação profunda e concomitante do próprio Ministério da Educação. Isso não quer dizer que se deva abolir toda forma de controle, eliminar a figura do credenciamento e deixar a educação superior entregue inteiramente ao sabor do jogo do mercado, como acontece nos Estados Unidos. A educação é um serviço público, como o atendimento à saúde e, a população tem o direito a um atendimento honesto, de boa qualidade. É de responsabilidade do Estado democrático zelar para que isso aconteça. $O$ que precisa ser abolido é o controle no estilo D. João VI ou Capanema, que imagina o mesmo tipo de escola, com os mesmos cursos e os mesmos programas operando de norte a sul do país. $O$ credenciamento pelo Estado dos estabelecimentos de ensino, a adoção de normas mínimas para seu reconhecimento, a exigência da apresentação de projetos educacionais sérios e competentes e a fiscalização dos serviços prestados não podem ser dispensados.

Uma diversificação do sistema significa também uma diversificação das fontes de financiamento. Não há porque fazer depender todo o sistema público exclusivamente de recursos federais. A combinação de contribuições estaduais, municipais e federais pode permitir a multiplicação dos estabelecimentos, ao mesmo tempo que constitui uma garantia de maior autonomia relativa. Certamente seria inviável, a curto prazo, eliminar o ensino privado; a longo prazo, seria desnecessário e indesejável. Também não há porquê impecir a associação de fundos públicos e privados em iniciativas locais, que podem atender necessidades específicas do mercado de trabalho. O fundamental, em tudo isso, é estabelecer um sistema de controle sobre o acesso e o uso 
dos recursos públicos de forma a garantir sua utilização no interesse da população, e com o intuito de promover uma elevação geral do nível do ensino superior hoje ministrado no país.

Finalmente, a idéia da diversidade aplica-se também ao campo da pesquisa e ao papel que ela deve desempenhar no sistema de ensino.

O ensino superior não é apenas o lugar da transmissão de um conhecimento acabado, mas da reflexão crítica, da produção de um novo saber e do domínio das técnicas para essa produção. A universidade, especialmente, é um lugar privilegiado para o desenvolvimento da pesquisa, porque é o único no qual a associação com o ensino não apenas dinamiza o processo didático, mas, inclusive, permite a reprodução dos investigadores e cientistas.

Estabelecer a indissociabilidade entre ensino e pesquisa, entretanto, não significa que todo estabelecimento de ensino seja, simultaneamente, um centro de pesquisas "de ponta" Isso subordinaria a expansão do ensino aos enormes investimentos materiais e humanos que essa pesquisa requer. Quando falamos em indissociabilidade entre ensino e pesquisa no ensino superior em geral, queremos dizer que deve haver atividade de pesquisa na instituição, que os docentes devem possuir o treinamento necessário para ter acesso aos novos conhecimentos que estão sendo produzidos em seu campo e a capacidade de utilizá-los criticamente no ensino. Os professores devem também ter a possibilidade de realizar pesquisas próprias, que constituem a forma por excelência de sua formação e atualização. Nas universidades, a pesquisa deve receber uma ênfase muito maior.

Quando pensamos portanto em um sistema de ensino superior diversificado, devemos pensar no desenvolvimento da universidade como uma instituição que, por sua natureza, por sua amplitude e pelos recursos de que dispõe, seja um centro de pesquisa privilegiado, capaz de alimentar e estimular as investigações nas instituições menores e promover a formação de docentes do ensino superior, de cientistas e pesquisadores de alto nível através da pós-graduação. Isso também não significa que todas as universidades sejam centros de excelência em todas as áreas do conhecimento. A expectativa seria irrealista - nesse campo também, um certo grau de diversidade e especialização é necessário. 
Se a universidade deve promover a pesquisa, é importante reconhecer que isso não pode ser feito por decreto. O Brasil já tentou por diversas vezes esse caminho e sem resultado. $O$ desenvolvimento da pesquisa (como do ensino) depende, em primeiro lugar, da qualificação do corpo docente. A estruturação da carreira em função da aquisição de qualificação, a vinculação da promoção à titulação acadêmica e a exigência de qualificação e titulação para o exercício das funções de direção da universidade são condições necessárias desse processo. Por outro lado, a institucionalização da pesquisa na universidade exige uma transformação de sua organização interna, que promova a formação de centros de pesquisa como parte integrante da universidade e institua o treinamento em pesquisa como elemento indispensável da formação do estudante.

Mas o problema não é só esse. A pesquisa não é feita apenas nos estabelecimentos de ensino superior, mas em outras instituições públicas e privadas especializadas. A indissociabilidade entre ensino e pesquisa exige o estabelecimento de mecanismos de comunicação entre as universidades e essas instituições.

Essa concepção envolve um papel novo para a universidade não o de monopolizar o ensino e a pesquisa, mas de se constituir como centro de dinamização e comunicação num sistema amplo e diversificado. Isso exige quebrar o isolamento da universidade e atribuir-lhe um papel para o qual ela não está preparada. Por isso mesmo, uma reforma da universidade deve ser um processo a longo prazo, pois envolve, entre outras coisas, superar resistências que provêm de atitudes tradicionalistas, de interesses particularistas de um corporativismo exacerbado.

A reforma da universidade é a reforma de todo o sistema de ensino no sentido de torná-lo mais diversificado e mais flexível: Esse processo não pode ocorrer dentro de rígidos controles burocráticos. Mas a eliminação desses controles pode significar um desenvolvimento caótico, que acarretaria a pulverização dos recursos sem qualquer garantia de uma melhoria do ensino e de um efetivo esforço para atender às demandas legítimas da população. $\mathrm{O}$ quc se faz necessário é um novo sistema de controle, mais moderno, mais flexivel e mais democrático. A completa autonomia das universidades e dos estabelecimentos de ensino superior, a total liberdade para as instituições fa- 
zerem o que quiserem e utilizarem como entenderem os fundos públicos, não pode ser aceita pela sociedade que os fornece, nem pelo Estado democrático que deve zelar pela sua aplicação. $O$ que precisa ser abolido é a rígida regulamentação do processo administrativo e a multiplicação de exigências meramente formais que sufocam as universidades e impedem iniciativas criadoras. É preciso que a educação superior seja pensada menos como funcionalismo público e mais como serviço público. $O$ encaminhamento de um processo de reforma, não pode dispensar o planejamento e a avaliação como instrumentos indispensáveis para a criação de um novo sistema de ensino no Brasil.

A solução de boa parte dos problemas aqui apontados não estão incluídos no conjunto de propostas apresentadas como reivindicações por grupos e movimentos sociais organizados. Esses, necessariamente, priorizam a solução de problemas tópicos e setoriais que afetam diretamente seus interesses. Daí, obviamente, a dificuldade de encaminhar um processo de reforma, pois freqüentemente os interesses mais gerais da sociedade não fazem parte das demandas explicitas de amplos movimentos sociais e só podem ser contemplados ferindo interesse de grupos organizados. $\dot{E}$ de organismos amplos e heterogêneos, como o CRUB, onde os interesses particularistas se acham diluídos, que se deve esperar uma pressão que contrabalance o particularismo das reivindicações setoriais.

Resta ainda uma observação final. $O$ ensino público brasileiro tem sofrido de excesso de regulamentação e falta de qualidade. Todo o sistema precisa ser transformado e diversificado, mas os rumos não estão claros. O que a situação exige é uma nova política para a educação superior, que oriente o período de transformação, que seja sensível à possibilidade de criar o novo, suficientemente corajosa para enfrentar os problemas e flexivel o bastante para mudar de rumo quando necessário. Por outro lado, as reivindicações hoje apresentadas por setores organizados da sociedade civil têm sempre um objetivo imediatista e tendem a exigir o remédio para os sintomas, mais do que propor a solução das causas dos problemas - aliás, é natural que assim seja. Num momento como este, em que se instala a constituinte, é fundamental que se evite uma regulamentação excessiva do ensino superior, a qual, com o intuito de resolver a crise nos seus aspectos conjunturais, acabe por criar uma outra camisa de força que impeça o encaminhamento futuro de soluções mais inovadoras. 


\section{BIBLIOGRAFIA CITADA}

BEN-DAVID, Joseph:Centers of Pearning: Britain, France, Germany, United States. Berkeley, The Carnegie Comission on Higher Education, 1977.

BLUME, Stuart S.: Elite and mass higler education: changing systems for changing circunstances. Trabalho apresentado no seminário "O futuro das profissões: credencialismo e constituinte" Brasilia, mimeo. s.d.

CARDOSO, Ruth: "Movimentos sociais urbanos: balanço crítico" Em Sociedade e Politica no Brasil pós 64 por Sorj, Bernardo e Tavares de Almeida, Maria Hermínia, organizadores. S. Paulo, Ed. Brasiliense; 1983.

CUNHA, Luiz Antônio: "Universidade: ensino público ou liberdade de ensino?" Em Bori, Carolina e outros (org.) Universidade brasileira: organizaçāo e problemas. Suplemento de Ciência e Cultura, vol. 37, n? 7, julho 1985.

DURHAM, Eunice Ribeiro: "Movimentos Sociais: a construção da cidadania". Em Novos Estudos CEBRAP n? 10, out. 1984.

DURHAM, Eunice Ribeiro: "A universidade brasileira - os impasses da transformação". A ser publicado em Ciência e Cultura, dezembro 1986.

FISCHER-APPELT, Peter: The future of university as a research institution. The Kellog Foundation Fijtieth Aniversary Lecture. Washington D.C., The Kellog Foundation, 1980.

GIANNOTTI, José Arthur: A universidade em ritmo de barbárie. S. Paulo, Ed. Brasiliense, 1986.

OLIVEIRA, João Batista Araújo e: "A burocratização da universidade" Em Bori, Carolina e outros (org.). Universidade brasileira: organização e problemas. Suplemento de Ciência e Cultura, vol. 37, n? 7, julho 1985.

OLIVEIRA, João Batista Araújo e: llhas de competência. Carreiras científicas no Brasil. S. Paulo, Brasiliense, CNPq, 1985.

MATTOS, Pedro Lincoln Carneiro Leão de: "Quadro histórico da política de supervisão e controle do Governo sobre as universidades federais autárquicas". Em Bori, Carolina e outros (org.). Universidade brasileira: organizą̧ão e problemas. Suplemento de Ciência e Cultura, vol. 37, n? 7, julho 1985.

SCHWARTZ, Laurent: Para salvar a universidade. S. Paulo, Ed. T.A. Queiroz - EDUSP, 1984.

SCHWARTZMAN, Simon: Formação da comunidade científica no Brasil. S. Paulo, Ed. Nacional, 1979.

SCHWARTZMAN, Simon; BOMENY, Helena Maria Bousquet; COSTA, Vanda Maria: Tempos de Capanema. S. Paulo, Paz e Terra - EDUSP, 1984.

TRAMONTIN, Raulino e BRAGA, Ronald: "O ensino superior particular no Brasil: traços de um perfil" Em Bori, Carolina e outros (org.) Universidade brasileira: organização e problemas. Suplemento de Ciência e Cultura, vol. 37, n? 7, julho 1985.

\section{FICHA CATALOGRÁFICA}

DURHAM, Eunice R. A reforma da Universidade. Revista da Universidade de São Paulo. São Paulo, (4): p. 9 - 42, março de 1987. 